\title{
Quality Improvement of College Students' Innovation and Entrepreneurship Education Based on Big Data Analysis under the Background of Cloud Computing
}

\author{
Wenhui Zhang (ii) \\ Qingdao HuanghaiUniversity, Qingdao, Shandong 266555, China \\ Correspondence should be addressed to Wenhui Zhang; zhangwh02@qdhhc.edu.cn
}

Received 1 December 2021; Revised 29 December 2021; Accepted 22 January 2022; Published 10 February 2022

Academic Editor: Wenming Cao

Copyright (c) 2022 Wenhui Zhang. This is an open access article distributed under the Creative Commons Attribution License, which permits unrestricted use, distribution, and reproduction in any medium, provided the original work is properly cited.

\begin{abstract}
China is in a critical period of national rejuvenation and national prosperity. Innovation is the soul of a nation and an inexhaustible driving force for national development. Youth are the hope and future of a country. In order to enable young people to have the entrepreneurial ability and innovative spirit of the development of the new era, it has become a very important link for college students to better enter the society and realize their own value. It has become a key link in the development of individuals and China, and has attracted the attention of the whole society. With the continuous development of Internet technology and the deepening of application exploration, in the context of cloud computing, the improvement of the quality of college students' innovation and entrepreneurship education based on big data analysis has also become the focus of universities, society, and the country. The core of the system is the discrete dynamic modeling technology of complex systems. This paper will discuss ways to improve the quality of college students' innovation and entrepreneurship education based on big data under the background of cloud computing by introducing the development and principle of complex system discrete dynamic modeling technology and analyzing the deficiencies and problems of college students' innovation and entrepreneurship quality in many aspects.
\end{abstract}

\section{Introduction}

In the process of production practice, people often encounter some complex events. The emergence and disappearance of these events are often random, rather than following a specific mathematical or physical law. Discrete event dynamic systems [1] (DEDS) are dynamic systems driven by such asynchronous and abrupt events. With the rapid development of science and technology, production, and life, there are more and more kinds of discrete event dynamic systems, which are applied in all aspects. The common fields are production practice, aerospace [2], communication, and military. After years of development and research, discrete event dynamic system has developed into a multimodel, multilevel, and multifaceted system, which can be used to analyze and predict the development and trend of events [3].
The quality of college students' innovation and entrepreneurship education [4] also conforms to the category of discrete event dynamic system. The quality of innovation and entrepreneurship education depends on various factors, and these factors are distributed discretely. These discrete events interact according to certain laws in order to meet certain quality requirements. With the enhancement of China's national strength, the improvement of its international status, and the improvement of industrialization, the single traditional economic model originally relied on has begun to change to an innovative and diversified modern economic model [5]. With the development of science and technology, cloud computing, big data, artificial intelligence, and other concepts have entered all aspects of people's life. Today's society has moved from tradition to modernity, from workers and farmers to informatization. This requires college students in the new era to adapt to a more changeable 
social environment. They also hope that college students who go out of the campus are talents with pioneering spirit, rather than traditional conservatism. Therefore, schools, society, and the state pay more and more attention to college students' innovation and entrepreneurship education. However, over the years, there have been many problems to improve and improve the quality of college students' innovation and entrepreneurship education. Therefore, in this paper, we hope to rely on cloud computing [6], analyze big data through complex system discrete dynamic modeling technology, timely predict and evaluate college students' innovation and entrepreneurship education, and design a perfect quality improvement path.

By introducing the development and principle of complex system discrete dynamic modeling technology, this paper discusses how to improve the quality of college students' innovation and entrepreneurship education based on big data under the background of cloud computing. There are many aspects of innovation and entrepreneurship quality. Innovative contributions include the following: (1) it has changed college students' concept of innovation and entrepreneurship. The school can organize a special team of teachers to provide students with professional and personalized services and improve students' interest in innovation and entrepreneurship, (2) analyze the deficiencies and problems of college students' innovation and entrepreneurship education, so that college students have the courage to innovate and practice, (3) improve the quality evaluation system of innovation and entrepreneurship and provide sufficient funds for college students' innovation and entrepreneurship practice, improve the practice guarantee of college students' innovation and entrepreneurship, and improve the project incubation rate and business transformation rate, and (4) through the big data analysis platform, realize the organic connection between the school and society, strengthen the business value of college students' innovation and entrepreneurship projects and establish a business value evaluation system. This research strengthens the learning and application ability of colleges and universities and teachers to learn cloud computing and big data, learn to use data analysis and evaluation, and use data to promote the quality of innovation and entrepreneurship education

This paper is divided into five parts. The first part expounds the research background and analyzes the deficiencies and problems of college students' innovation and entrepreneurship education. The second part makes a reference to the research of related work. The third part introduces the development, principle, and research methods of discrete dynamic modeling technology for complex systems. The research methods are further elaborated. The fourth part expounds the results and points out the problems of college students' low awareness and participation in innovation and entrepreneurship, uneven distribution of innovation and entrepreneurship education, imperfect top-level design, obvious homogenization, and generally low incubation rate of innovation and entrepreneurship. It also analyzes the reasons for the failure of college students' innovation and entrepreneurship incubation rate. Finally, it summarizes the full text, which provides guidance for young people to have the entrepreneurial ability and innovative spirit of the development of the new era.

\section{The Related Works}

Discrete event dynamic system first appeared in queuing phenomenon [7] and network research. In queuing, the whole system follows a set of artificial rules rather than the so-called physical or mathematical logic or laws [8]. With the development of computer and other technologies, Weingartene et al. formally put forward the concept of discrete event dynamic system [9] around 1980. At that time, people paid more and more attention to discrete event dynamic system and hoped to develop some man-made systems to deal with discrete events in the fields of communication, production, transportation, and military with the help of intelligent technology, Therefore, this term also refers to this kind of man-made system. During this period, people's research on man-made systems and performance [10] greatly promoted the emergence and development of the theory of discrete event dynamic systems.

Discrete event dynamic system is now roughly defined as a dynamic system with asynchronous and sudden event driven state evolution [11]. The most basic problem in the research of discrete event dynamic system is modeling [12]. According to the levels of logic, time, and statistical performance, we can divide the distributed event dynamic system into logic level model, time level model, and statistical performance level model [13]. These three models have developed very well and formed their respective theoretical frameworks.

China's research on discrete event dynamic system has made great progress from the implementation of 863 high-tech computer integrated manufacturing system theme plan [14] in 1987. In the following three years [15], it has conducted extensive research and development on logical hierarchical model, time hierarchical model, and statistical performance hierarchical model and achieved very valuable achievements. For example, Liu F's research on the centralized diagnosis of discrete event dynamic system [16]. Wang Shouguang researched the attack of information physical system under the framework of discrete event system [17]. Zhang Wenggang studied DEDS designed for flow shop to solve the coordination control problem [18]. Dai et al. analyzed the flow characteristics of knowledge workers in high-tech enterprises according to nonlinear discrete dynamic system modeling [19]. Zhang studied the application of discrete event dynamic system in network simulation [20]. Wang et al. studied the modeling and repair capability analysis of military aircraft repair line [21]. In recent ten years, the research on the modeling mode and behavior characteristics of discrete event dynamic system of manufacturing system has become a very important research proposition in the world [22]. 


\section{Research Method}

Discrete event is the basic component of discrete event dynamic system [23] and the inducement leading to the change of discrete dynamic system. It has three basic characteristics: uniqueness, asynchrony, and subjectivity [24]. Compared with continuous dynamic system, discrete event dynamic system only changes in discrete time. Its changes are asynchronous, concurrent, and uncertain. It cannot be modeled in a conventional way like continuous dynamic system, but through special human rules [25]. Figure 1 is a conceptual diagram of a discrete event dynamic system.

The queuing system consists of arrival mode, service desk, and queuing rules. For the arrival mode, the arrival law was described, and the average arrival interval is $t$. The system is a common statistical performance hierarchical model in discrete event dynamic systems. In the queuing network, many service centers form a system through a certain structure, and each service center can include multiple service desks.

In the queuing system, the arrival model we choose is the Poisson distribution with the parameter $\lambda$, the service time obeys the exponential distribution with the parameter $\mu$, and the stay time $W$ of the customer in the system, in the single service center model $M / M / 1$, obeys the negative exponential distribution of the parameter $\mu-\lambda$, the average stay time is $E$ $[W]$, and the average waiting time is equal to the average stay time minus the service time.

According to normalization conditions,

$$
\sum_{n=0}^{\infty} p_{n}=1, \rho=\frac{\lambda}{\mu}<1 .
$$

$N$ is the number of customers, $P_{n}$ is the steady-state probability with the number of customers $n, \lambda$ is the average speed of the input customer flow, and $\mu$ is the average service rate.

It can be obtained that the steady-state probability distribution of customers is

$$
P_{n}=P^{n}(1-\rho) n \geq 1 .
$$

The steady-state average number of customers $L$ is

$$
L=\frac{\lambda}{\mu-\lambda} \text {. }
$$

The steady-state average pair length $L_{q}$ is

$$
L_{q}=\frac{\lambda^{2}}{\mu(\mu-\lambda)} .
$$

The average waiting time $w_{q}$ of customers is

$$
w_{q}=\frac{\lambda}{\mu(\mu-\lambda)} .
$$

The steady-state average stay time $w$ of customers is

$$
w=\frac{1}{\mu-\lambda} \text {. }
$$

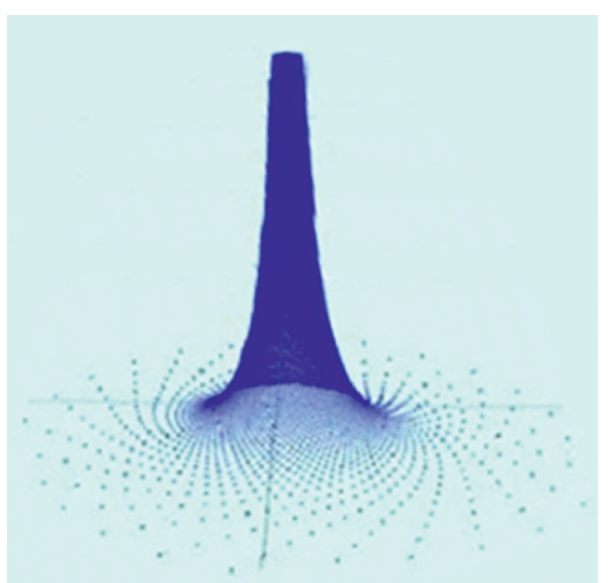

Figure 1: Discrete dynamic modeling of complex systems.

Little formula holds in $M / M / c$ system as follows:

$$
\lambda w_{q}=L_{q}, \lambda w=L .
$$

According to the steady-state performance analysis of $M / M / C$ and the normalization condition (1), the steady-state probability distribution of customers is

$$
\begin{gathered}
p_{0}=\left[\sum_{n=0}^{c-1} \frac{\rho^{n}}{n !}+\frac{c \rho^{c}}{c !(c-\rho)}\right]^{-1}, \\
p_{n}=\left\{\begin{array}{ll}
\frac{\rho^{n}}{n !} p_{0} & n \leq c \\
\frac{\rho^{n}}{c^{n-c} c !} p_{0} & n<c
\end{array} \quad \rho=\frac{\lambda}{\mu}\right.
\end{gathered}
$$

The steady-state average pair length is

$$
L_{q}=\left[\frac{(\lambda / \mu)^{c} \lambda \mu}{(c-1) !(c \mu-\lambda)^{2}}\right] p_{0} .
$$

The average waiting time of customers is

$$
w_{q}=\left[\frac{(\lambda / \mu)^{c} \lambda \mu}{(c-1) !(c \mu-\lambda)^{2}}\right] p_{0} .
$$

The steady-state average residence time is

$$
w=\left[\frac{(\lambda / \mu)^{c} \mu}{(c-1) !(c \mu-\lambda)^{2}}\right] p_{0}+\frac{1}{\mu} .
$$

Steady-state average number of customers is as follows:

$$
L=\left[\frac{(\lambda / \mu)^{c} \lambda \mu}{(c-1) !(c \mu-\lambda)^{2}}\right] p_{0}+\frac{\lambda}{\mu} .
$$

Under the condition of the existence of the solution of the steady-state probability distribution, if the accretion and extinction rates of the birth and death process $N(t)$ are bounded, that is, the supremum $\sup _{n}\left\{\lambda_{n-1}\right\}<\infty$, $\sup _{n}\left\{\mu_{n}\right\}<\infty$, the necessary and sufficient condition for the existence of the steady-state probability distribution of the birth and death process $N(t)$ is as follows: 


$$
\sum_{n=1}^{\infty} \prod_{i=1}^{n} \frac{\lambda_{i-1}}{\mu_{i}}<\infty
$$

When the steady-state probability distribution $\left\{p_{n}\right\}$ exists, the parametric expression of $p_{n}$

$$
p_{n}=p_{0} \prod_{i=1}^{n} \frac{\lambda_{i-1}}{\mu_{i}}, p_{0}=\left[1+\sum_{n=1}^{n} \coprod_{i=1}^{n} \frac{\lambda_{i-1}}{\mu_{i}}\right]^{-1} \text {. }
$$

For the research topic of improving the quality of college students' innovation and entrepreneurship education, in addition to the modeling of discrete event dynamic system itself, it also needs to be organically combined with other technologies such as big data to build an innovation and entrepreneurship education quality system. Figure 2 shows the application process of big data in innovation and entrepreneurship education. It can be found that, in this application system, data is very important for the presentation of results. Among them, the acquisition, integration, and screening of data will affect the analysis and prediction of the system.

Among them, the data acquisition channels can be roughly divided into eight categories, including management data, capital data, industry data, scientific and technological innovation data, policy data, market demand data, resource data, and university education model. It is hoped that through the objective understanding and mining of these eight kinds of big data, we can make a comprehensive analysis of the policies and practices of schools, society, and the state on college students' innovation and entrepreneurship. We can also analyze different data, predict later results, and put forward improvement schemes.

According to the data characteristics of college students' innovation and entrepreneurship education, we designed an education quality improvement path for complex system discrete dynamic modeling technology, as shown in Figure 3, hoping to improve the quality of college students' innovation and entrepreneurship education in China in the future. We subdivide the service desk into three layers: collection and storage layer, analysis and visualization layer, and statistical evaluation layer. Through the analysis of different discrete events in the innovation and entrepreneurship education database, we can find the relationship between them and the impact on the results. Finally, we can help us quickly analyze and predict the results, including the guidance direction of entrepreneurship programs, evaluate and analyze innovation and entrepreneurship, predict risks, and analyze and evaluate the level of teachers.

Based on big data analysis and complex system discrete dynamic modeling technology, this paper studies and compares the quality of innovation and entrepreneurship education of college students in national key universities and key universities in foreign developed countries and obtains the following results and analysis contents, hoping to help establish a platform for improving the quality of innovation and entrepreneurship education of college students.

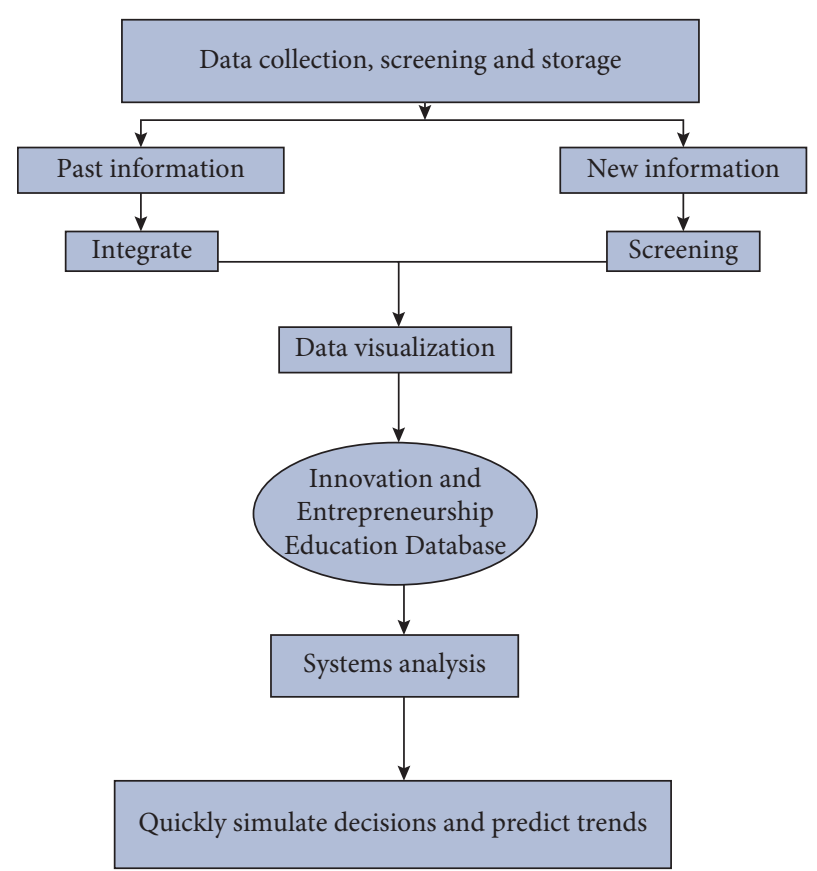

Figure 2: Application process of big data in innovation and entrepreneurship education.

\section{Results and Analysis}

4.1. College Students' Awareness and Participation in Innovation and Entrepreneurship Are Not High Enough. Research Object and Data Source. In the survey, college students from different colleges were selected as the research object, and the samples were randomly investigated in classrooms, study rooms, dormitories, and other student gathering places in their spare time. The questionnaire was distributed on-site, and the big data was obtained by recovering the effective questionnaire. The questionnaire consists of three parts: the first is the basic situation; the second is the questionnaire of entrepreneurial intention; the third is the questionnaire of innovation intention. The big data analysis on the willingness and participation of national college students in innovation and entrepreneurship education is shown in Figure $4.12 \%$ of college students are not interested in or understand innovation and entrepreneurship education, only $4 \%$ of college students have plans to start a business after graduation, and $41 \%$ of college students have received relevant theoretical knowledge of innovation and entrepreneurship, However, only $19 \%$ of college students have really participated in practical projects of innovation and entrepreneurship. The lack of awareness and participation of college students in innovation and entrepreneurship is mainly due to the lack of guidance from the school and society, as well as the imperfect establishment of policies and security system in all aspects. The school's management mode of innovation and entrepreneurship cannot cover all students enough to arouse the interest and attention of all students, mostly relying on students' initiative and willingness or academic credit requirements. On the other hand, it is related to college students' own 


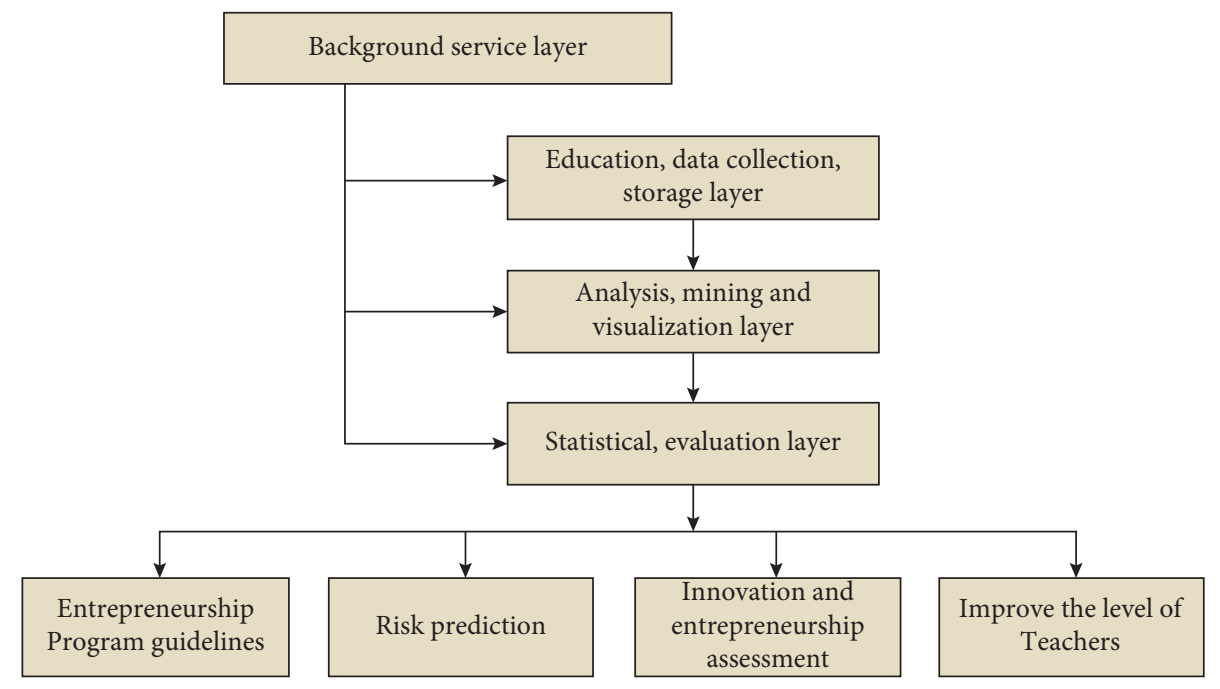

Figure 3: Ways to improve the quality of college students' innovation and entrepreneurship education under big data.

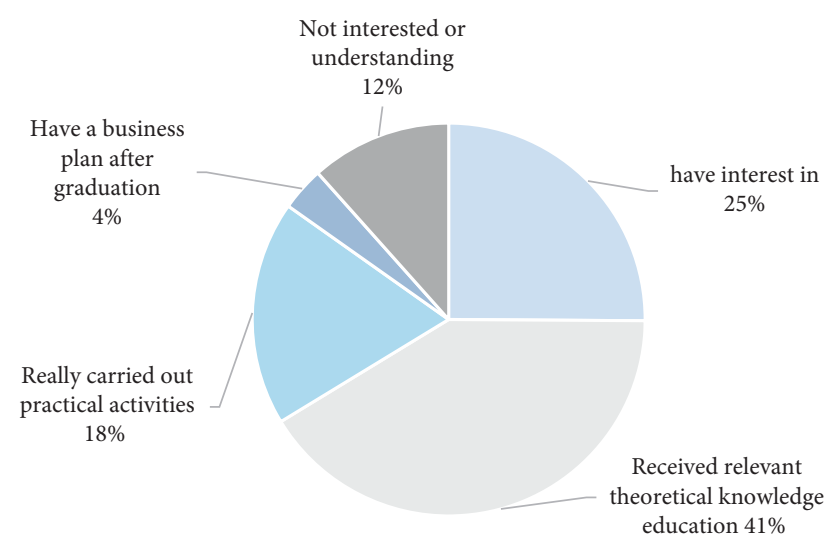

FIGURE 4: Survey on innovation and entrepreneurship awareness and participation.

personality and growth experience and generally lack the spirit of innovation and pioneering practice. In the past, under the responsive education system, college students only paid attention to and cared about the selective examination, and most college students' intention after graduation is to stabilize the traditional work, so they do not pay much attention to the practice of innovation and entrepreneurship.

\subsection{The Distribution of College Students' Innovation and} Entrepreneurship Education in China Is Uneven. Through the big data investigation and analysis of the distribution and development of national college students' innovation and entrepreneurship education, Figure 5 is obtained, which can show the general distribution of national innovation and entrepreneurship education. As can be seen from the figure, compared with the economically developed coastal and southern regions in China, such as Beijing, Jiangsu, and Guangzhou, the provinces with better development of innovation and entrepreneurship education, and the remote and economically backward provinces such as Xinjiang and

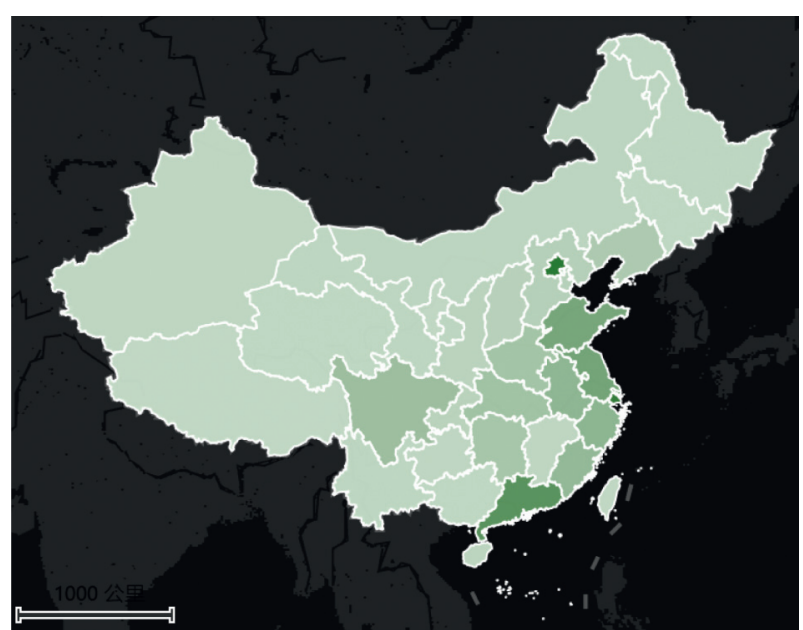

Figure 5: National innovation and entrepreneurship distribution map.

Gansu in the northwest and southwest, the development of innovation and entrepreneurship education for college students is still relatively weak. On the whole, the distribution of innovation and entrepreneurship education in China shows an unbalanced trend. It is preliminarily speculated that the reason for this situation is related to the financial support and policy preference of local provinces, cities, and universities for college students' innovation and entrepreneurship education. These schools have given better support and actively created a practice environment, which not only makes college students more interested and involved, but also ensures the more stable and smooth development of innovation and entrepreneurship practice activities. Then, the success rate and total number of college students' innovation and entrepreneurship practice are improved. Areas with weak innovation and entrepreneurship development can learn from excellent provinces to formulate policies and change the school management mode. 
4.3. The Top-Level Design of College Students' Innovation and Entrepreneurship Education Is Not Perfect. We further analyzed and visualized the big data of the top-level design of college students' innovation and entrepreneurship education in colleges and universities across the country and drew a model diagram of the top-level design, as shown in Figure 6. We can see that colleges and universities mostly focus on courses and speeches, in which course design accounts for a large proportion, and practice is mostly carried out in the form of competition, which is relatively single. In addition, when college students carry out innovation and entrepreneurship activities, they lack the guidance and help of professional elders and encounter problems that are not easy to solve, and there is a shortage of funds, which is not enough to support the smooth development of the activities, which is easy to make the project die prematurely or uncompleted halfway. The school's policy is not very perfect, and it does not pay enough attention to innovation and entrepreneurship education. The unreasonable top-level design will make it difficult to improve the quality of college students' innovation and entrepreneurship education, and there is no substantive promotion, which cannot really mobilize college students' enthusiasm and explore students' innovation and practice ability.

\subsection{The Homogenization of College Students' Innovation and} Entrepreneurship Is Obvious. In the big data analysis of college students' innovation and entrepreneurship projects, we get Figure 7 . When analyzing and extracting the keywords selected for innovation and entrepreneurship practice, we find that there is an obvious homogenization of college students' innovation and entrepreneurship projects, and there is an obvious phenomenon of following the crowd in content selection. They are carried out in groups and lack of innovative spirit in content. The form of the project is too single, and there is no scene of a hundred flowers blooming. At the same time, the innovation and entrepreneurship projects of college students are too conservative, which is also contrary to the original intention of innovation and entrepreneurship education. In other aspects, it is found that the practicality of college students' innovation and entrepreneurship is not strong, and most of the innovation and entrepreneurship activities are not well incubated, and the business conversion rate is very low. This homogenization phenomenon is contrary to our original intention of carrying out innovation and entrepreneurship education. We hope to see college students innovate and practice boldly, inject vitality into social development and progress, achieve a career, and transport more excellent talents in line with the development of the times.

4.5. The Incubation Rate of Innovation and Entrepreneurship of Various Projects Is Generally Not High. According to the big data analysis of the incubation rate of college students' innovation and entrepreneurship projects, as shown in Figure 8 , we mainly divide the projects into six categories: high-tech field, chain franchise field, intellectual service field, store opening, technological entrepreneurship, and other categories. The incubation rate of innovation and entrepreneurship practice in high-tech neighborhood and intellectual service neighborhood is relatively high, and the incubation rate of entity entrepreneurship is relatively low. However, on the whole, the incubation rate of all college students' innovation and entrepreneurship projects is very low, which shows that the commercial conversion rate of college students' innovation and entrepreneurship projects in school can bring very low expectations of economic benefits in the future. This is a problem worthy of thinking and analysis, which will be analyzed later.

\subsection{There Is Still a Gap between College Students' Innovation} and Entrepreneurship Education in China and Developed Countries. This paper also makes a horizontal big data comparative analysis of innovation and entrepreneurship education at home and abroad, as shown in Figure 9. It compares the five levels: the flexibility of the education system, the promotion of social atmosphere, the superiority of the education system, the participation of college students in innovation and entrepreneurship, and the success rate and conversion rate of college students' innovation and entrepreneurship. Through comparison, we can see that the education system of colleges and universities in developed countries is more flexible, which is conducive to the development of innovation and entrepreneurship activities and stimulate students' innovative spirit. The social atmosphere in developed countries is also more promotive, which is conducive to the effective connection between schools and society, and can improve the commercial conversion rate of innovation and entrepreneurship. Therefore, the innovation and entrepreneurship enthusiasm of college students in developed countries are also much higher than the domestic students, and the practical success rate and commercial conversion rate of innovation and entrepreneurship are many times higher than the domestic students. However, the superiority of China's education system should be obviously stronger than that of developed countries, which is our characteristic and strength. While improving and developing other aspects, maintaining and giving full play to the superiority of the education system with Chinese characteristics is our direction and goal.

4.7. Analysis on the Failure of College Students' Innovation and Entrepreneurship Incubation Rate. Finally, we analyze the reasons for the failure of college students' innovation and entrepreneurship incubation rate according to big data, as shown in Figure 10. The failure reasons are mainly divided into six factors: lack of funds, weak team professional ability, lack of policy support, problems of teachers' team level, low students' willingness, and lack of professional guidance. Based on the analysis of specific factors one by one, students' willingness is low. Most students only regard innovation and entrepreneurship practice as a means to obtain credits and a voucher for future work, rather than as a way to cultivate ability and practice of innovation and entrepreneurship. Therefore, they do not attach great importance to the incubation rate of the project and the conversion rate of 


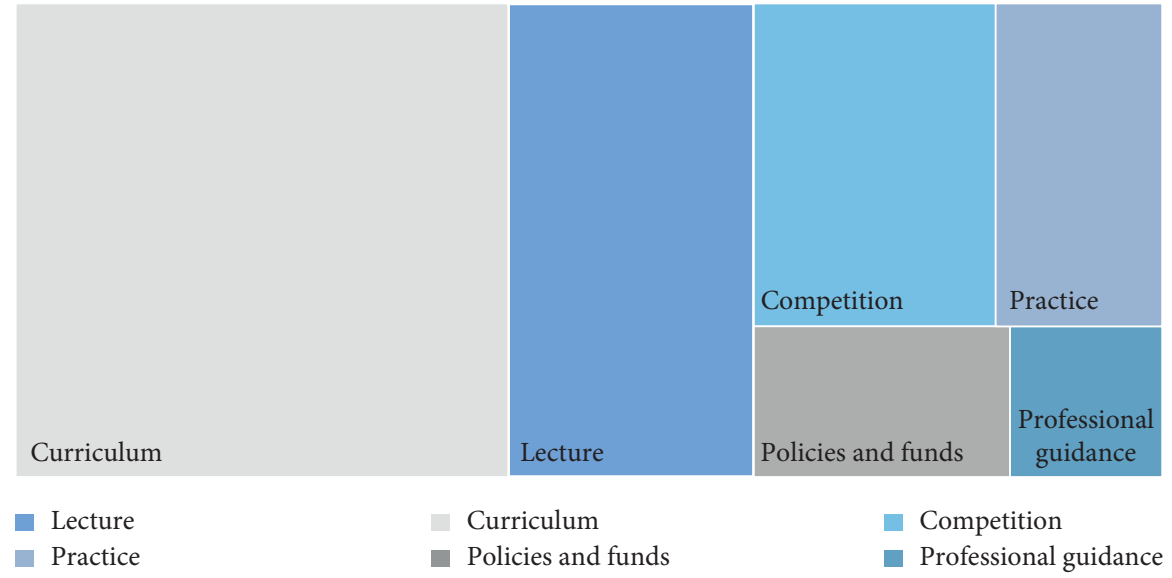

FIGURE 6: Research on top-level design of innovation and entrepreneurship in colleges and universities.

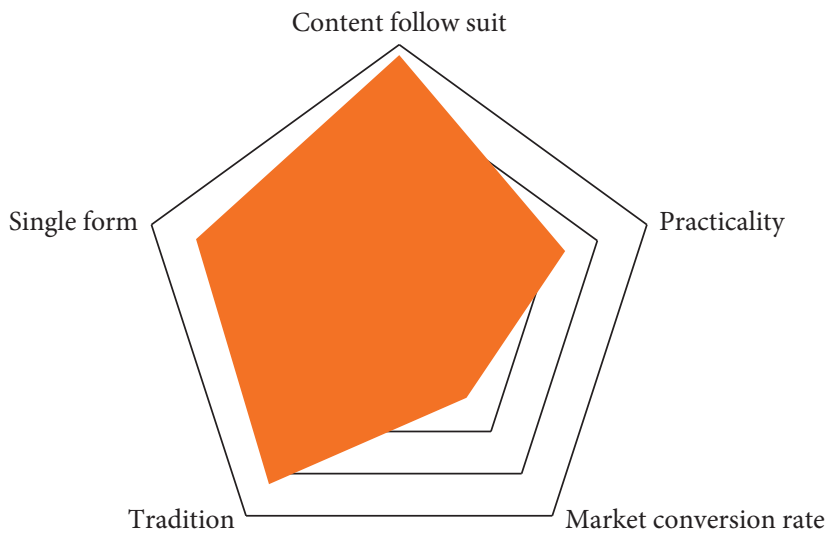

FIGURE 7: Homogeneity analysis of innovation and entrepreneurship.

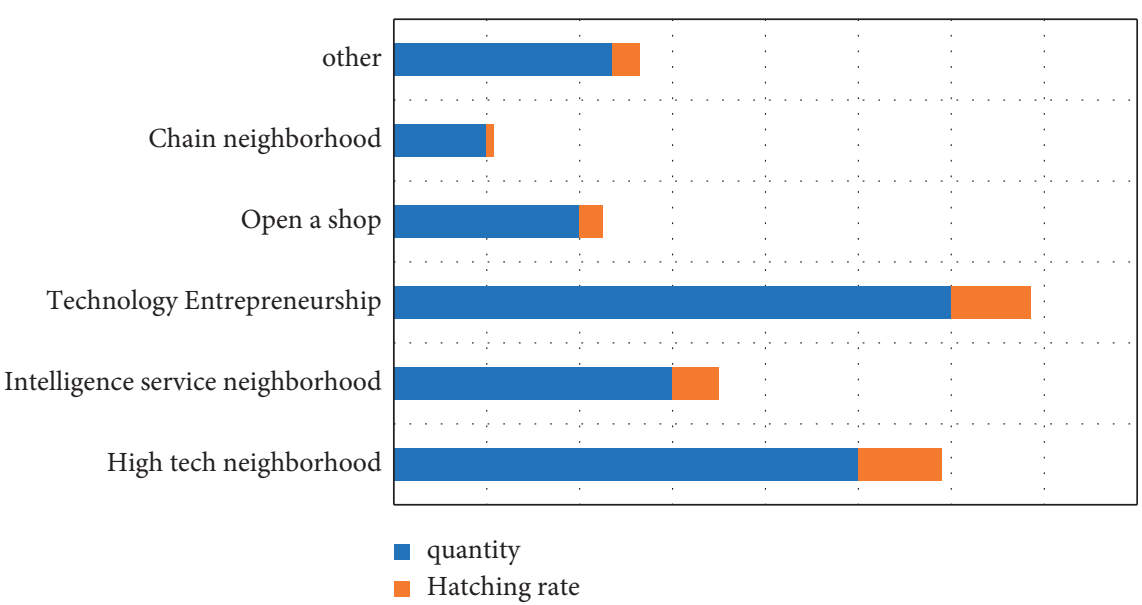

FIGURE 8: Investigation on incubation rate of innovation and entrepreneurship.

business, and it can be seen from the above. The homogeneity of college students' innovation and entrepreneurship is obvious. Students' entrepreneurship lacks innovation and is too traditional and conservative, which is not conducive to improving college students' entrepreneurial enthusiasm.
On the other hand, the low willingness of college students to innovate and start a business is partly due to the lack of funds in the process of project practice, which makes the whole entrepreneurial process difficult and frustrating. In addition, there is no special teacher for guidance, and the 


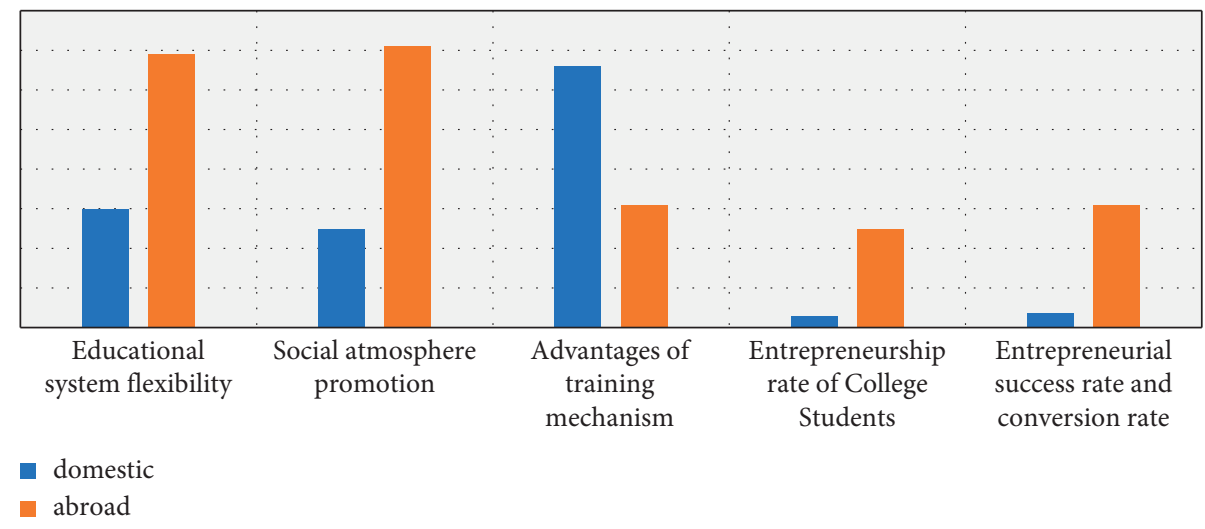

FIGURE 9: Comparison of innovation and entrepreneurship at home and abroad.

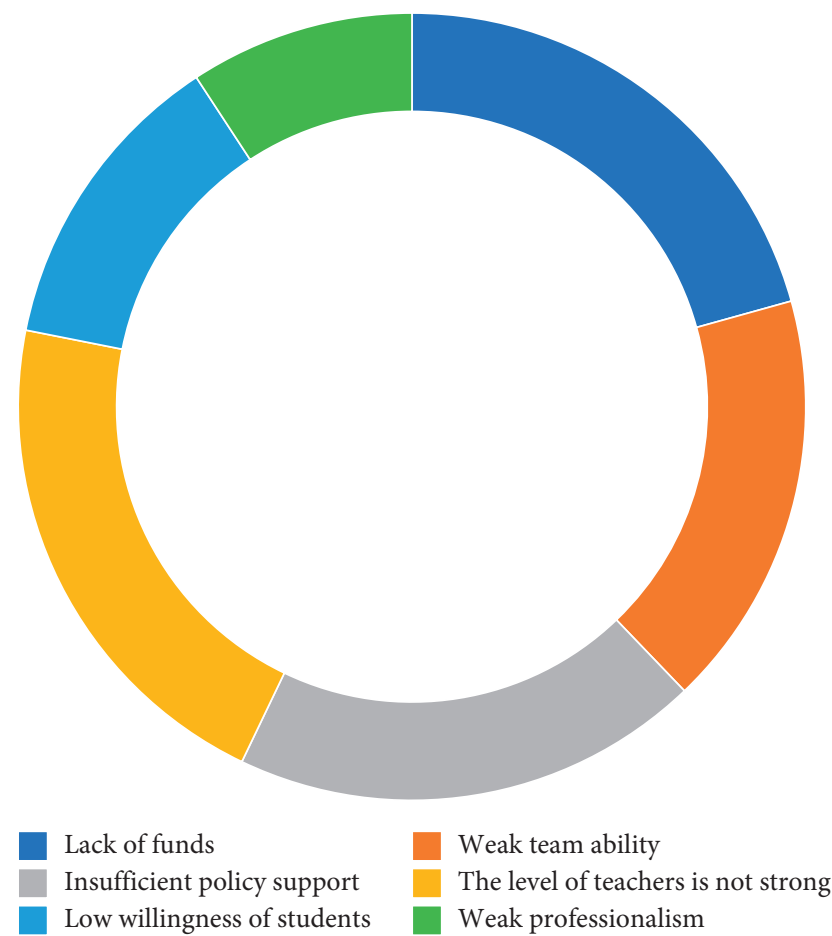

FIGURE 10: Reasons for failure of innovation and entrepreneurship incubation rate.

professional ability of the team is weak, which is not enough to support the later incubation of the project. From the previously mentioned data, it is not difficult to find that the practice way of college students' innovation and entrepreneurship is mainly through competition, and the competition is mainly to pursue novelty and novelty. Sometimes, it will cause pseudoinnovation and cannot produce commercial value, which is also one of the reasons for the low hatching rate. These reasons for failure can be guided and improved through innovation and entrepreneurship policies, but at present, the government's management of innovation and entrepreneurship education needs to be further strengthened.

\section{Countermeasures to Improve the Entrepreneurship Rate of College Students}

5.1. Strengthening Entrepreneurship Training for College Students. Constructing college students' entrepreneurship education system and improving college students' entrepreneurship literacy are the most important factors to improve the success rate of college students' entrepreneurship. As colleges and universities, first, we should build a curriculum system, form layered and classified curriculum modules, teach entrepreneurship basic courses in the lower grades, and gradually introduce entrepreneurship practice courses in the higher grades. Second, we should explore the reform of curriculum system and introduce flexible school system. Third, we focused on providing entrepreneurship practice training programs and encouraged college students to actively participate in entrepreneurship competitions and entrepreneurship training programs. In addition, some colleges and universities offer entrepreneurship classes for students with entrepreneurial intention, which is a more effective way. For college students themselves, they should actively learn entrepreneurial knowledge, actively carry out entrepreneurial practice, and constantly accumulate entrepreneurial experience.

5.2. Improving College Students' Entrepreneurship Policy. From the perspective of the government, we should formulate entrepreneurship policies for university and provincial groups in terms of laws and regulations, taxation, registration, and business handling and lower the policy threshold based on necessary preference. From the perspective of colleges and universities, we should introduce policies to encourage college students to start businesses.

5.3. Building a Platform for College Students' Entrepreneurship. Colleges and universities should break the barriers between colleges and markets, build a win-win entrepreneurial platform, and introduce investors and 
entrepreneurs into the entrepreneurial platform. Conditional colleges and universities can even move the entrepreneurship platform off campus to truly accept the market test, so that students can be tempered in the real market.

\section{Conclusion}

Based on the previously mentioned analysis of the current situation of college students' innovation and entrepreneurship education quality based on big data analysis in the context of cloud computing, it is not difficult to find that at present. There are still many problems to be solved for college students' innovation and entrepreneurship in China, and there is also a large gap with developed countries. The main manifestations are that students' enthusiasm is not high enough, and their cognition and understanding of innovation and entrepreneurship are not clear enough. The policy and financial support of colleges and universities and the state for innovation and entrepreneurship are not enough to ensure the normal development and incubation of college students. The teaching staff is also very weak, and there is no special teacher to provide guidance. There are also problems in the connection between universities and society. The social environment and insufficient attention to college students' innovation and entrepreneurship are also one of the reasons for the low rate of business transformation.

Through the discrete dynamic modeling technology of complex systems and the storage, processing, and analysis technology of big data mining, we have realized the recombination and visualization of data, found the internal relationship between discrete events, clearly seen the existing problems of college students' innovation and entrepreneurship, and found the path to improve the quality of innovation and entrepreneurship education. First, in the future, it is suggested to change the concept of college students' innovation and entrepreneurship. The school can organize a special team of teachers, provide students with professional and personalized services, and improve students' interest in innovation and entrepreneurship. Second, let college students be bold in innovation and practice. Third, improve the quality evaluation system of innovation and entrepreneurship and provide sufficient funds for college students' innovation and entrepreneurship practice, so as to improve the guarantee for college students' innovation and entrepreneurship practice and improve the incubation rate and business conversion rate of the project; Fourth, through the big data analysis platform, we can realize the organic connection between schools and society, strengthen the business value of college students' innovation and entrepreneurship projects, and establish a business value evaluation system. Fifth, universities and teachers should strengthen the learning and application ability of cloud computing and big data, learn to use data analysis and evaluation, and use data to drive the quality of innovation and entrepreneurship education. However, this paper does not have an in-depth discussion on the specific conditions that college students should have for innovation and entrepreneurship, which needs to be investigated in the future research. We hope this paper can help improve the quality of college students' innovation and entrepreneurship education and contribute to national development and talent training.

\section{Data Availability}

The data used to support the findings of this study are available from the corresponding author upon request.

\section{Conflicts of Interest}

The author declares that there are no conflicts of interest.

\section{Acknowledgments}

This work was supported by the Qingdao Huanghai University.

\section{References}

[1] Y. Feng, "Route queuing model of railway 12306 call center," Railway Computer Application, vol. 27, no. 9, pp. 17-20, 2018.

[2] R. Hu and Y. H. Tang, "The transient queue length distribution of $M / G / 1$ queueing system withdelayed vacation and min (N,V)-policy," Journal of Mathematics in Practice and Theory, vol. 49, no. 13, pp. 145-155, 2019.

[3] J. X. Li, T. Dai, and C. M. Ye, "Service design of distributed contact centers in cloud computing," Journal of University of Shanghai for Science and Technology, vol. 36, no. 4, pp. 338-344, 2014.

[4] X. Eryong and J. Li, "What is the ultimate education task in China? Exploring "strengthen moral education for cultivating people"("Li De Shu Ren")," Educational Philosophy and Theory, vol. 53, no. 2, pp. 128-139, 2021.

[5] X. Xu and Y. Ye, Curriculum Design and Effectiveness Evaluation of Entrepreneurship Education -- Taking the MOOC Course of Fundamentals of Entrepreneurship Education of Zhejiang University as a Sampleno. (1), Journal of East China Normal University, Shanghai of China, 2018.

[6] G. Gao and L. Li, Research on the Evaluation and Promotion Strategy of the Effectiveness of Entrepreneurship Education in Colleges and Universitiesno. (2), Journal of East China Normal University, Shanghai of China, 2016.

[7] D. Zheng and Q. C. Zhao, Discrete Event Dynamic System, pp. 1-10, Tsinghua University Press, Beijing, 2001.

[8] A. Choudhury and P. Medhi, "Balking and reneging in multiserver Markovian queuing system," International Journal of Mathematics in Operational Research, vol. 3, no. 4, pp. 377-394, 2011.

[9] E. Weingarten, S. Bhatia, and B. Mellers, "MultipleGoals as reference points: one failure makes everything else feel worse," Management Science, vol. 65, no. 7, pp. 3337-3352, 2018.

[10] X. W. Hu, R. C. Wang, and X. L. Wang, "Model and algorithm for the shift scheduling and rosteringproblem of call centers with shift-type constraints," Industrial Engineering \& Management, vol. 25, no. 2, pp. 51-58, 2020.

[11] I. Bychkov, A. Kazakov, A. Lempert, and M. Zharkov, "Modeling of railway stations based on queuing networks," Applied Sciences, vol. 11, no. 5, p. 2425, 2021.

[12] J. X. Li and X. N. Wang, "Shift scheduling based on fatigue and routing capacity limitation in contactcenters," Journal of Applied Sciences, vol. 36, no. 6, pp. 122-135, 2018. 
[13] V. Mehrotra, K. Ross, G. Ryder, and Y.-P. Zhou, "Routing to manage resolution and waiting time in call centers with heterogeneous servers," Manufacturing \& Service Operations Management, vol. 14, no. 1, pp. 66-81, 2012.

[14] S. Mattia, F. Rossi, M. Servilio, and S. Smriglio, "Staffing and scheduling flexible call centers by two-stage robust optimization," Omega, vol. 72, pp. 25-37, 2017.

[15] Z. Y. Hu and J. Nasiry, "Are markets with loss-AverseConsumers more sensitive to losses," Management Science, vol. 64, no. 3, pp. 1384-1395, 2017.

[16] F. Liu, "Safe diagnosability of fuzzy discrete-event systems and a polynomial-time verification," IEEE Transactions on Fuzzy Systems, vol. 23, no. 5, pp. 1534-1544, 2015.

[17] S. Wang, Y. Zhao, D. you, and R. Ning, "A review of research on Information Physics system attack under the framework of discrete event system," Control and Decision Making, 2021.

[18] W. Zhang and C. Li, "On coordination control of A class of DEDS," Journal of Yangtze University(Natural Science Edition), vol. 16, no. 6, p. 120 124, 2019.

[19] D. Dai, Z. Cai, and B. Zhang, "Discrete dynamic system modeling and resilient control of knowledge workers in hightechnology enterprises," Journal of China University of Metrology, vol. 32, no. 1, 2021.

[20] G. Sathishkumar, "Bivariate regression adaptive wald's boost energy aware routing for Wsn with IoT," Turkish Journal of Computer and Mathematics Education (TURCOMAT), vol. 12, no. 7, pp. 2224-2241, 2021.

[21] P. Wang, Y. Chen, Z. Cai, and L chao, "Modeling and repair capability analysis of military overhaul line," Systems Engineering and Electronics, vol. 40, no. 6, 2018.

[22] M. K. Girish and J.-Q. Hu, "Higher order approximations for the single server queue with splitting, merging and feedback," European Journal of Operational Research, vol. 124, no. 3, pp. 447-467, 2000.

[23] B. Kim and J. Kim, "The waiting time distribution for a correlated queue with exponential interarrival and service times," Operations Research Letters, vol. 46, no. 2, pp. 268-271, 2018.

[24] S. K. Iyer and D. Manjunath, "Queues with dependency between interarrival and service times using mixtures of bivariates," Stochastic Models, vol. 22, no. 1, pp. 3-20, 2006.

[25] G. Panda, A. D. Banik, and M. L. Chaudhry, "Stationary distributions of the $\mathrm{R}[\mathrm{X}] / \mathrm{R} / 1$ cross-correlated queue," Communications in Statistics-Theory and Methods, vol. 46, no. 17, pp. 8666-8689, 2017. 